\title{
Personality and Drunk Driving: Identification of DUI Types Using the Hogan Personality Inventory
}

\author{
Yola Nolan, John A. Johnson, and Aaron L. Pincus
}

\begin{abstract}
Two hundred persons arrested for driving under the influence (DUI), 30 social drinkers, 30 depressed patients, 30 incarcerated criminals, and 30 alcoholics completed the Hogan Personality Inventory (HPI) and Court Reporting Network (CRN) interview. A cluster analysis of HPI scores for the DUI group revealed 5 personality types: Impulsive-Extravert, Normal, Neurotic-Introvert, NeuroticHostile, and Unassertive-Conformist. The types differed predictably on demographic variables, drinking behavior, and driving records as assessed by the CRN. The Impulsive-Extravert and Normal types had HPI profiles similar to social drinkers. The Neurotic-Introvert type most resembled depressed patients, and the Neurotic-Hostile type most resembled incarcerated criminals. Results clarify previous findings on DUI personality types and establish a basis for tailoring therapeutic treatments to different types of DUI offenders.
\end{abstract}

Recent advances in the field of personality structure have converged, providing a consensus regarding the superordinate personality dimensions underlying a comprehensive taxonomy of personality traits (Digman, 1990; McCrae \& John, 1992). The Five-Factor Model (FFM) of personality hierarchically organizes personality traits into five basic dimensions: I. Extraversion, II. Agreeableness, III. Conscientiousness, IV. Emotional Stability (vs. Neuroticism), and V. Intellect or Openness to Experience. These dimensions broadly assess important individual differences in interpersonal, motivational, emotional, attitudinal, and experiential style. This convergence has provided a working model allowing personality psychologists to proceed with the conceptual and empirical tasks they have long set for

Yola Nolan, CONCERNS Counseling and Consultation Firm, DuBois, Pennsylvania; John A. Johnson, Department of Psychology, Pennsylvania State University, DuBois Campus; Aaron L. Pincus, Department of Psychology Pennsylvania State University, University Park Campus.

This article is based on a dissertation written by Yola Nolan under the supervision of John A. Johnson in partial fulfillment of the requirements for a PhD from the Professional School of Psychological Studies. San Diego, California. Portions of the data reported here were presented at the 97th Annual Convention of the American Psychological Association in New Orleans, Louisiana, August, 1989.

Some of the writing of this article was completed by John A. Johnson while he was a visiting research fellow at Universität Bielefeld, Bielefeld, Germany, supported by a fellowship from the Alexander von Humboldt-Stiftung. He wishes to express his gratitude to the psychology department at Bielefeld and the von Humboldt-Stiftung for their support during that time

We also thank James Fugate, MD, Medical Director, ClearfieldJefferson Community Mental Health Center; Rita Kartavich, MSA, Assistant Administrator of Outreach, DuBois Regional Medical Center; and Robert Dombrosky, Warden, Clearfield County Jail, for their assistance in our data-gathering. We also thank Michael Gerg for assisting us in the data analysis and all persons who volunteered to participate in this study.

Correspondence concerning this article should be addressed to Yola Nolan, CONCERNS, 90 Beaver Drive, DuBois, Pennsylvania 15801. themselves (Wiggins, 1992). Thus, there is currently a large body of research activity applying the FFM to diverse and important realms of inquiry including psychotherapy (Miller, 1991), psychopathology (e.g., Widiger \& Trull, 1992; Wiggins \& Pincus, 1989), clinical assessment (e.g., Costa \& McCrae, 1992a, 1992b; Muten, 1991), health psychology (Smith \& Williams, 1992), job performance (Barrick \& Mount, 1991), and close relationships (Buss, 1992).

Previous work investigating personality characteristics of driving-under-the-influence (DUI) offenders and personality variables associated with drunk-driving accidents has suggested that the population of DUI offenders contains distinct personality subtypes (Donovan \& Marlatt, 1982) and that personality variables play a greater role in drunk-driving accidents than clinical alcoholism (Clay, 1972; Donovan, Marlatt, \& Salzberg, 1983; Donovan, Queissler, Salzberg, \& Umlauf, 1985; Scoles, Fine, \& Steer, 1984; Snowdon, 1984). This work was conducted and interpreted before the emergence and application of the FFM of personality. In this article we investigate the personality types found in a sample of DUI offenders from an FFM framework using a well-validated measure of the FFM, the Hogan Personality Inventory (HPI; R. Hogan, 1986). The HPI is one of the major instruments available to assess the FFM (Briggs, 1992; Trapnell, Wiggins, \& Broughton, 1992; Wiggins \& Pincus, 1992, in press; Wiggins \& Trapnell, in press). Research using the HPI has emphasized predictive validity, particularly in occupational settings (e.g., J. Hogan \& Hogan, 1986), and the incorporation of Hogan Assessment Systems has furthered development and market applications of the HPI in government and industry. The theoretically grounded HPI, with its excellent track record across diverse, applied settings, may prove to be a useful instrument for identifying personality types at risk for DUI and for understanding, preventing, and correcting drunkdriving behaviors.

\section{Reconceptualizing Donovan and Marlatt's DUI Types in Terms of the Five Factor Model}

Our study has a number of empirical goals and hypotheses. First, we attempted to replicate Donovan and Marlatt's (1982) 
DUI personality subtypes with a better validated measure of personality. They identified their personality subtypes on the basis of cluster analysis of a questionnaire containing demographic variables, questions assessing drinking-related behaviors, and 17 short scales measuring driving attitudes and personality traits linked to accident risk in past research. We combined the clinical experience of Y. Nolan in treating DUI clients with an FFM interpretation of Donovan and Marlatt's (1982) empirically derived DUI clusters to generate our hypotheses regarding personality subtypes in our sample. Consistent with previous investigations, we expected to find significant differences in both personality styles and important demographic and drunk-driving variables across DUI personality types.

The descriptions for these hypothesized types were informed by Johnson's (in press; Johnson \& Ostendorf, 1993) analysis of FFM-based types. Following a suggestion made by Hofstee and De Raad (1992), Johnson labeled profile patterns according to pairs of scales on which individuals receive relatively high or low scores. For example, an individual scoring high on Extraversion but low on Agreeableness is labeled a Domineering Type or I + II - Type.

\section{Hypothesized FFM High-Point Codes for DUI Types}

\section{Impulsive-Extravert $(I+I I I-)$}

Donovan and Marlatt (1982) identified a relatively assertive, uninhibited, externally oriented DUI group at moderate risk relative to other clusters. They exhibited good social adjustment and relatively light drinking. We hypothesized that from an FFM perspective, such a DUI group would present as extraverted and impulsive.

\section{Neurotic-Introvert $(I-I V-)$}

Donovan and Marlatt (1982) found a relatively unassertive, depressed, inhibited, irritable DUI cluster with little sense of personal control in their lives. This cluster was at relatively greater risk for DUI. From an FFM perspective, we predicted such a group would present as neurotic and introverted.

\section{Neurotic-Hostile $(I I-I V-)$}

Donovan and Marlatt (1982) identified an aggressive, poorly adjusted, sensation-seeking, heavy drinking DUI cluster also at relatively high risk for DUI. From an FFM perspective, we predicted such a group would present as neurotic and hostile.

\section{Unassertive-Conformist $(I-V-)$}

Donovan and Marlatt (1982) found a DUI cluster that also drank heavily but otherwise reported adequate adjustment and relatively few accidents. They considered this cluster to be similar to but less deviant than the Neurotic-Hostile cluster; however, data indicated that this group appeared to be preoccupied with maintaining a sense of personal control; was significantly less hostile, resentful, competitive, and irritable; and more inhibited than the former cluster. The individuals in this cluster seemed unassertive and lacking in drive and energy, preferring to maintain a sense of control. From an FFM perspective, we hypothesized that such a group may be better described as unassertive (rather than neurotic) and conformist (rather than hostile) in using alcohol to reduce tension.

\section{Normal}

Donovan and Marlatt (1982) also found a cluster with no discernibly abnormal characteristics. Compared with other clusters, this group had higher social status, a good driving record, and relatively low levels of drinking. We had no a priori hypothesis regarding the FFM description of such a cluster, although we predicted the members would not present as significantly maladjusted.

Socioanalytic theory (R. Hogan, 1983) regards psychological disorders as forms of self-presentation that are continuous with forms of self-presentation in the normal population. However, Lorr and Strack (1993) pointed out that subgroups based on FFM dimensions may differ across different types of populations. We therefore selected four comparison groups, which we predicted would demonstrate differential similarity to derived DUI clusters, to more accurately interpret the characteristics of cluster members. Specifically, we predicted that ImpulsiveExtravert DUIs and Normal DUIs would be most similar to a group of social drinkers, Neurotic-Introvert DUIs would be most similar to a group of depressed patients, and NeuroticHostile DUIs would be most similar to a group of incarcerated criminals. We also included a comparison group of alcoholics.

\section{Method}

\section{Overview}

We cluster analyzed HPI scores for a group of first time DUI offenders. We used three different clustering methods and then compared the similarity of cluster solutions. Following cluster identification, we compared these offender types on variables not included in the original cluster analysis. These included age, income, drinking attitudes, behavioral impairment from drinking, and quantity and frequency of alcohol consumption. We then compared HPI profiles from our DUI clusters with non-DUI comparison groups including social drinkers, clinically depressed patients, incarcerated criminals, and clinical alcoholics.

\section{Subjects}

DUIS. This sample consisted of 200 first time DUI offenders (184 males, 16 females; average age 32.47 years) arrested for driving a motor vehicle while at the "per se level" of intoxication (.10 blood alcohol level in Pennsylvania, measured by certified breath or blood testing). ${ }^{1}$ Subjects were referred to $Y$. Nolan for evaluation by the county court system. Two subjects were African-American, the remainder were White. In this sample, $22.5 \%$ were single, $38.5 \%$ were married, $33.0 \%$ were separated, $3.5 \%$ were divorced, and $2.5 \%$ were widowed.

With regard to occupation, $34.7 \%$ were unemployed; $27.2 \%$ were unskilled or semiskilled workers (e.g., custodian); $12.7 \%$ were skilled workers (e.g., mechanic); 9.8\% worked in clerical, sales, or technician positions (e.g., bookkeeper); $12.1 \%$ worked as midlevel professionals (e.g., manager); and $3.5 \%$ were professionals (e.g., lawyer). Years of formal education ranged from a minimum of 5 years to a maximum of 19 years, with a mean of 11.7 years.

\footnotetext{
${ }^{1}$ All subjects were volunteers who participated without compensation. Individuals arrested for DUI were excluded from comparison groups.
} 
Social drinkers. This comparison group consisted of 30 social drinkers ( 6 males, 24 females; average age 33.0 years) who responded to an advertisement to participate in the study. These persons reported ingesting no more than two drinks per day, had never experienced life problems through the use of alcohol, and had no alcohol related health problems. One subject was Asian, the remainder were White. In this sample, $76.7 \%$ were married, $20.0 \%$ were single, and $3.3 \%$ were divorced. With regard to occupation, $26.7 \%$ were unemployed; $3.3 \%$ were unskilled or semiskilled workers; $10.0 \%$ were skilled workers; $16.7 \%$ worked in clerical, sales, or technician positions; $30.0 \%$ worked as midlevel professionals; and $13.3 \%$ were professionals. Years of formal education ranged from a minimum of 10 years to a maximum of 20 years, with a mean of 14.3 years.

Depressed patients. The second comparison group consisted of 30 patients from a rural Pennsylvania community mental health center $(6$ male, 24 female; average age 36.9 years) who were diagnosed as depressed upon intake with the Minnesota Multiphasic Personality Inventory (MMPI) and who were still being treated at the time for depression. Subjects were recruited by the director of the center. All subjects were White. In this sample, $33.3 \%$ were married, $26.7 \%$ were single, $10.0 \%$ were separated, $26.7 \%$ were divorced, and $3.3 \%$ were widowed. With regard to occupation, $60.0 \%$ were unemployed; $0.0 \%$ were unskilled or semiskilled workers; $3.3 \%$ were skilled workers; $13.3 \%$ worked in clerical, sales, or technician positions; $23.3 \%$ worked as midlevel professionals; and $0.0 \%$ were professionals. Years of formal education ranged from a minimum of 6 years to a maximum of 19 years, with a mean of 12.8 years.

Incarcerated criminals. The third comparison group consisted of 30 criminals ( 26 male, 4 female; average age 28.7 years) serving jail terms in a Pennsylvania county prison for reasons other than driving under the influence. Subjects were recruited by the prison warden. Two prisoners described themselves as Hispanic, the remainder were White. In this sample, $26.7 \%$ were married, $50.0 \%$ were single, $3.3 \%$ were separated, $16.7 \%$ were divorced, and $3.3 \%$ were widowed. With regard to occupation, $83.3 \%$ were unemployed; $3.3 \%$ were unskilled or semiskilled workers; $0.0 \%$ were skilled workers; $10.0 \%$ worked in clerical, sales, or technician positions; $3.3 \%$ worked as midlevel professionals; and $0.0 \%$ were professionals. Years of formal education ranged from a minimum of 9 years to a maximum of 16 years, with a mean of 11.8 years.

Alcoholics. The final comparison group consisted of 30 alcoholics (23 male, 7 female; average age 29.3 years) recruited from drug and alcohol agencies, Alcoholics Anonymous, and hospital and rehabilitation centers in rural northwest Pennsylvania. All subjects were White. In this sample, $26.7 \%$ were married, $33.3 \%$ were single, $20.0 \%$ were separated, $16.7 \%$ were divorced, and $3.3 \%$ were widowed. With regard to occupation, $76.7 \%$ were unemployed; $13.3 \%$ were unskilled or semiskilled workers; $6.7 \%$ were skilled workers; $0.0 \%$ worked in clerical, sales, or technician positions; $3.3 \%$ worked as midlevel professionals; and 3.3\% were professionals. Years of formal education ranged from a minimum of 7 years to a maximum of 16 years, with a mean of 10.9 years.

\section{Measures}

After signing an informed consent form, all subjects completed the HPI (R. Hogan, 1986). The HPI is a 310 item true-false self-report inventory assessing a six-factor variant of the FFM of personality (Briggs, 1992; McCrae \& John, 1992). The HPI also contains a short validity scale to check for careless responding. Alpha reliabilities for scales range from .76 to .89 ; 4-week test-retest reliabilities range from .74 to .99 . The scales have been validated in samples (total $N>2,000$ ) of adult men and women employed in a variety of occupations ( $R$. Hogan, 1986).

Y. Nolan, who is trained in administration and scoring, administered the Court Reporting Network Evaluation (CRN; Scoles \& Cook, 1986).
The CRN evaluation consists of 87 questions that the interviewee answers in a 40-minute session. The CRN contains several items concerning such basic demographic information as age, sex, and income. The CRN also contains three scales: the Mortimer-Filkins (MF) index, which identifies factors related to problem drinking; an impairment index (IMP), which measures alcohol-related physical and psychological impairment; and a quantity-frequency index of alcohol consumption (QF).

The MF is an empirically constructed scale, organized around areas of marital and family problems, recent stress, financial difficulties, personal adjustment problems, previous arrests, driving history, and alcohol dependence. Scoles and Cook (1986) reported a split-half reliability coefficient of .97 and validity coefficient (point-biserial correlation between an alcoholic and control group) of .92 for the $M f$ scale.

The IMP consists of 12 items assessing behavioral problems caused by excessive alcohol use (blackouts, shakes, missing meals or work, etc.). The QF measures the amount and frequency of beer, wine, and liquor consumption within a 30-day period. A separate QF for each beverage is calculated by multiplying the self-reported frequency of consumption (in a month) by the self-reported quantity consumed (on an average occasion) by the estimated proportion of ethanol content (by volume) in the beverage. The total QF index is the sum of the individual beverage indices. Both the IMP and the QF have been extensively field tested and validated by the National Institute on Alcohol Abuse and Alcoholism. The QF index has been criticized for using "five or more drinks" as the upper bound for assessing quantity consumed. This potentially creates artificially low ceiling effects in assessment.

\section{Analyses}

The program $k$-means (PKM) routine from the BMDP statistical package (Dixon et al., 1983) was applied to the standardized scores on the six primary HPI scales for the 200 DUI offenders. PKM uses a $k$ means clustering technique and establishes a fixed number of homogeneous groups of cases using Euclidean distances (Lorr, 1983). PKM begins with all cases assigned to one cluster. The program repeatedly splits this and subsequent clusters until it produces a requested number of clusters. Cases are iteratively reassigned to a cluster whose center (mean) is closest, as measured by Euclidean distance.

Lorr and Suziedelis (1990) have indicated that more than two dozen arbitrary rules exist for determining how many clusters one should extract in an analysis; several Monte Carlo studies have compared the utility and validity of these rules when used with a variety of cluster analysis programs (e.g., Milligan, 1981). These studies indicated that performance of cluster algorithms can vary with data characteristics although some are relatively more consistent than others (Milligan \& Cooper, 1985). We selected a $k$-means algorithm for initial cluster derivation because this procedure produces "excellent recovery of structures when the starting seeds are obtained from the group-average method or when valid a priori information is available" (Lorr, 1983, p. 117). Because we hypothesized finding FFM-based clusters similar to those previously identified by Donovan and Marlatt (1982), the PKM program was instructed to identify five clusters. This decision was also influenced by the suggestion that cluster analyses of measures of personality from both normal and alcoholic populations generally identify four to seven cluster types (Lorr \& Strack, 1993; Lorr \& Suziedelis, 1990).

To assess the stability of the five-cluster solution, we conducted two additional cluster analyses. First, we used the cluster means from the PKM solution to define initial seeds for a Quick Cluster analysis (SPSS, 1988) of HPI scores. Quick Cluster begins with one cluster and iteratively reassigns cases to the nearest cluster according to squared Euclidean distance until the requested number of clusters is reached.

Finally, Ward's (1963) hierarchical clustering procedure from the Cluster routine (SPSS, 1988) was applied to the HPI scores. Unlike the two previous techniques, which subdivide the entire sample into smaller clusters, this procedure begins with individual cases and iteratively ag- 
Table 1

Hogan Personality Inventory (HPI) Profiles for Driving-Under-the-Influence Clusters and Comparison Groups

\begin{tabular}{|c|c|c|c|c|c|c|c|c|c|c|c|}
\hline \multirow[b]{2}{*}{$\begin{array}{l}\text { HPI } \\
\text { factors }\end{array}$} & \multicolumn{11}{|c|}{ Cluster or group } \\
\hline & $\begin{array}{l}\text { Impulsive- } \\
\text { Extravert }\end{array}$ & Normals & $\begin{array}{l}\text { Neurotic- } \\
\text { Introvert }\end{array}$ & $\begin{array}{l}\text { Neurotic- } \\
\text { Hostile }\end{array}$ & $\begin{array}{l}\text { Unassertive- } \\
\text { Conformist }\end{array}$ & Total DUI & $F(4,195)$ & $\begin{array}{c}\text { Social } \\
\text { drinkers }\end{array}$ & $\begin{array}{l}\text { Depressed } \\
\text { patients }\end{array}$ & Criminals & Alcoholics \\
\hline$N$ & 49 & 45 & 32 & 36 & 38 & 200 & - & 30 & 30 & 30 & 30 \\
\hline INT & 48.8 & 49.0 & 35.7 & 45.3 & 28.6 & 41.9 & $47.9^{*}$ & 45.2 & 40.3 & 46.2 & 40.9 \\
\hline ADJ & 46.7 & 50.7 & 33.4 & 31.4 & 46.2 & 42.6 & $48.3^{*}$ & 45.1 & 23.2 & 37.6 & 29.7 \\
\hline PRU & 41.3 & 58.3 & 44.4 & 44.2 & 56.2 & 49.4 & $36.2^{*}$ & 48.8 & 50.4 & 44.7 & 37.8 \\
\hline AMB & 49.8 & 41.4 & 32.8 & 47.9 & 28.4 & 40.7 & $48.7^{*}$ & 45.8 & 34.7 & 44.9 & 45.1 \\
\hline SOC & 55.7 & 43.0 & 40.7 & 48.9 & 42.0 & 46.6 & $37.0^{*}$ & 52.7 & 43.6 & 51.1 & 54.3 \\
\hline LIK & 52.0 & 55.4 & 42.0 & 32.4 & 47.8 & 46.8 & $67.0^{*}$ & 51.0 & 40.0 & 44.4 & 41.7 \\
\hline
\end{tabular}

Note. Bold means indicate smallest difference significant at the .05 level with a Scheffe posttest. $T$ scores computed from normative data

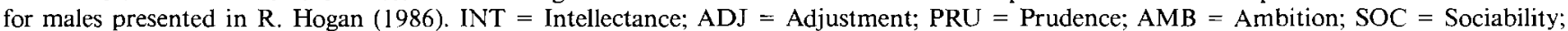
LIK $=$ Likability.

$* p<.001$.

glomerates them into larger and larger clusters by optimizing an objective function known as the within-groups sum of squares, or ESS (Lorr \& Strack, 1993). Merger of cases into clusters occurs on the basis of a minimum increase in ESS. The optimal number of clusters can be determined from this method by noting a marked discontinuity in the proximity coefficients between levels of clustering.

The groups identified through cluster analysis were then compared with an analysis of variance (ANOVA) with respect to demographic variables and the MF, IMP, and QF indices.

The similarities among DUI clusters and comparison group HPI profiles were examined through Mahalonobis $D^{2}$ values (Rao, 1952). Mahalanobis $D^{2}$ values provided a statistical test for significant multivariate differences between DUI clusters and comparison group profiles. We then examined relative similarities between the DUI clusters and comparison group profiles through Cronbach's $D^{2}$, a descriptive measure better suited for comparing profile similarity values (Cronbach \& Gleser, 1953; Wiggins, 1973). After we identified DUI and comparison group similarities, we compared groups through a discriminant function analysis program (Nie, Hull, Jenkins, Steinbrenner, \& Bent, 1975).
The intent was to determine whether cases from each DUI cluster would be misidentified most frequently as belonging to a particular comparison group and whether cases from the comparison groups would be misidentified most frequently as belonging to a particular DUI cluster. Such differentially linked "misidentifications" would provide additional indications of the degree of personality similarity between DUI subtypes and particular comparison groups.

\section{Results}

\section{Cluster Analyses}

The PKM clustering procedure partitioned the DUI sample into five groups with distinctive profiles on the HPI. A multivariate analysis of variance using cluster membership as the grouping variable and the six HPI scores as dependent variables produced an $F(6,190)$ value of $3604.94, p<.00001$. Univariate ANOVA showed significant differences among the clusters on every HPI scale (see Table 1).

Table 2

Court Reporting Network Evaluation (CRN) Profiles for Driving-Under-the-Influence Clusters and Comparison Groups

\begin{tabular}{|c|c|c|c|c|c|c|c|c|c|c|c|}
\hline \multirow[b]{2}{*}{$\begin{array}{c}\text { CRN } \\
\text { variables }\end{array}$} & \multicolumn{11}{|c|}{ Cluster or group } \\
\hline & $\begin{array}{l}\text { Impulsive- } \\
\text { Extravert }\end{array}$ & Normals & $\begin{array}{l}\text { Neurotic- } \\
\text { Introvert }\end{array}$ & $\begin{array}{l}\text { Neurotic- } \\
\text { Hostile }\end{array}$ & $\begin{array}{l}\text { Unassertive- } \\
\text { Conformist }\end{array}$ & $\begin{array}{l}\text { Total } \\
\text { DUI }\end{array}$ & $F(4,195)$ & $\begin{array}{c}\text { Social } \\
\text { drinkers }\end{array}$ & $\begin{array}{l}\text { Depressed } \\
\text { patients }\end{array}$ & Criminals & Alcoholics \\
\hline$N$ & 49 & 45 & 32 & 36 & 38 & 200 & - & 30 & 30 & 30 & 30 \\
\hline \multirow{2}{*}{ Age } & 31.0 & 34.0 & 29.3 & 28.6 & 38.9 & 32.5 & $4.39^{*}$ & 33.0 & 36.9 & 28.7 & 29.3 \\
\hline & 13.2 & 12.8 & 9.6 & 11.6 & 12.8 & 12.6 & & 11.9 & 12.3 & 8.0 & 10.6 \\
\hline \multirow[t]{2}{*}{ Inc } & 14,041 & 15,022 & 11,594 & 7,361 & 14,790 & 12,810 & $3.51^{*}$ & 20,233 & 19,448 & 7,607 & 10,567 \\
\hline & 10,077 & 12,754 & 10,245 & 6,779 & 11,376 & 10,807 & & 14,229 & 17,659 & 12,102 & 11,982 \\
\hline \multirow[t]{2}{*}{$\mathrm{MF}^{\mathrm{a}}$} & 48.2 & 48.8 & 71.1 & 71.7 & 63.7 & 59.2 & $5.33^{*}$ & 16.8 & 38.1 & 83.9 & 116.4 \\
\hline & 30.1 & 32.4 & 36.3 & 33.6 & 27.9 & 33.3 & & 14.2 & 27.2 & 44.3 & 33.3 \\
\hline \multirow[t]{2}{*}{$\mathrm{IMP}^{\mathrm{ab}}$} & 3.00 & 2.96 & 4.84 & 5.31 & 3.42 & 3.78 & $3.51^{*}$ & 0.64 & 0.43 & 6.67 & 14.07 \\
\hline & 2.33 & 3.39 & 4.03 & 5.30 & 2.94 & 3.72 & & 1.62 & 1.37 & 5.88 & 8.30 \\
\hline \multirow[t]{2}{*}{$\mathrm{QF}^{\mathrm{a}}$} & .72 & .71 & .72 & 1.04 & .73 & .78 & .40 & .15 & .06 & 2.96 & 4.39 \\
\hline & 1.23 & 1.56 & 1.17 & 1.60 & 1.30 & 1.38 & & .28 & .19 & 6.02 & 3.49 \\
\hline
\end{tabular}

Note. Standard deviations are reported below mean scores. Bold means indicate smallest difference significant at the .05 level with a Scheffe posttest. Inc = Income; $\mathrm{MF}=$ Mortimer-Filkins index; IMP = Impairment index; $\mathrm{QF}=$ Quantity/Frequency index.

${ }^{\mathrm{a}}$ Cut-offs for problem drinking (Scoles \& Cook, 1986): $\mathrm{MF}=25.0, \mathrm{IMP}=5.90, \mathrm{QF}=2.00$. ${ }^{\mathrm{b}}$ Overall ANOVA significant but no two groups different by Scheffe posttest.

${ }^{*} p<.01$. 
Table 3

Indices of Profile Similarity for Driving-Under-the-Influence (DUI) and Reference Groups

\begin{tabular}{lccrr}
\hline & \multicolumn{4}{c}{ Similarity to reference groups } \\
\cline { 2 - 5 } \multicolumn{1}{c}{ DUI clusters } & Social drinkers & Depressed patients & Criminals & Alcoholics \\
\hline Impulsive-Extravert & 43.74 & 486.00 & 73.50 & 216.00 \\
& 1.92 & 10.28 & 3.09 & 4.60 \\
Normal & 100.86 & 541.50 & 245.76 & 588.06 \\
& 2.84 & 11.54 & 4.96 & 11.41 \\
Neurotic-Introvert & 194.94 & 91.26 & 96.00 & 105.84 \\
Neurotic-Hostile & 7.70 & 3.85 & 4.63 & 3.01 \\
& 181.50 & 116.16 & 50.46 & 54.00 \\
Unassertive-Conformist & 6.74 & 4.28 & 2.18 & 2.13 \\
& 201.84 & 393.66 & 294.00 & 496.86 \\
& 8.90 & 9.32 & 8.98 & 11.26 \\
\hline
\end{tabular}

Note. Top number is Cronbach's $D^{2}$; second number is Mahalanobis $D^{2}$. The smaller the value of $D^{2}$, the more similar the groups. All Mahalanobis values are significant at the $p<.001$ level.

When the DUI cases were reclustered with the Quick Cluster method, $80 \%$ of the PKM Cluster 1 cases reemerged in the same cluster, $87 \%$ from PKM Cluster 2 remained together, $91 \%$ from PKM Cluster 3 remained together, $83 \%$ from PKM Cluster 4 reemerged together, and $89 \%$ of the PKM Cluster 5 cases reappeared in the same cluster. When subjected to the significantly different Ward's procedure, the following percentages of cases from PKM clusters one through five reemerged in the same cluster: $65 \%, 96 \%, 31 \%, 72 \%$, and $92 \%$. Only the third PKM cluster appeared somewhat unstable; Ward's procedure grouped a significant number (53\%) of cases from this cluster with Ward's Cluster 5 . The change in proximity coefficients between 3-cluster and 7-cluster levels of the grouping hierarchy indicated that either four or five clusters be considered optimal. Cluster membership was judged to be stable across methods, and the remaining analyses were based on the five clusters identified in the PKM analysis.

Univariate ANOVA across CRN variables revealed that DUI clusters differed significantly in terms of age, income, MF scores, and IMP, but not in terms of the QF Index. Means, expressed as $T$ scores based on normative data for the HPI ( $R$. Hogan, 1986), are shown for the DUI clusters and four comparison groups in Table 1; CRN information for all groups is shown in Table 2.

\section{HPI Profile Comparisons}

Table 3 shows both the Mahalonobis $D^{2}$ and Cronbach $D^{2}$ values of profile similarity. Mahalanobis $D^{2}$ values showed that all DUI cluster profiles differed significantly from the profiles of the four comparison groups. Thus, none of the DUI clusters was found to "belong to" a comparison population in a statistical sense. The Cronbach $D^{2}$ values clearly demonstrate, however, strong relative differences between each DUI cluster and the four non-DUI groups.

\section{Discriminant Analysis}

Only the first discriminant function showed an eigenvalue greater than unity (1.4). This function accounted for $46.5 \%$ of the variance and classified $62.5 \%$ of the 320 cases correctly. Ta- ble 4 shows the hit and miss rates for the discriminant analysis. The primary misclassifications aided in interpretation of the DUI clusters. For example, cases from the DUI Cluster 1 were misclassified most often as social drinkers and social drinkers were misclassified most often as Cluster 1 DUIs, indicating personality similarity between these two groups.

\section{Discussion}

The distinctive pattern of low and high scores on the HPI and CRN and on the relative similarity to the four comparison groups supported the existence of five distinct DUI types hypothesized at the outset of the study. A summary of DUI clusters' distinctive patterns follows.

\section{Cluster 1 (Impulsive-Extrovert)}

The HPI profile of the first DUI cluster is most similar to the profile of social drinkers. Both groups showed relatively flat profiles hovering about the $T=50$ level with a slight elevation on the Sociability $(\mathrm{I}+)$ scale. Cluster 1 differed from the social drinker group only in a somewhat lower Prudence scale (III-), indicating a greater degree of impulsivity and self-indulgence in the DUIs (R. Hogan, 1986). Cluster 1 had the second lowest IMP score (3.00), and the lowest MF score (48.2) of the five DUI clusters; nonetheless, the CRN manual states that MF scores greater than 38 suggest a pathological drinking pattern. These considerations led to the label Impulsive-Extravert for this DUI cluster.

\section{Cluster 2 (Normal)}

This cluster resembled the social drinkers more than any other comparison group, although the similarity is less than that found between the Impulsive-Extravert DUIs and social drinkers. Normal DUIs are characterized by average Intellectance and Adjustment, peaks on Prudence and Likability, and slightly depressed scores on Ambition and Sociability. The higher Prudence score and lower Ambition and Sociability scores distinguish Cluster 2 from the Impulsive-Extravert DUIs. People with profiles similar to Cluster $2 \mathrm{~s}$ are described by others with 
Table 4

Hit and Miss Rates for Group Identification from Discriminant Analysis

\begin{tabular}{|c|c|c|c|c|c|c|c|c|c|}
\hline \multirow[b]{2}{*}{ Group } & \multicolumn{9}{|c|}{ Percentage classified in each group } \\
\hline & 1 & 2 & 3 & 4 & 5 & 6 & 7 & 8 & 9 \\
\hline \multicolumn{10}{|l|}{ DUI types } \\
\hline 1. Impulsive-Extravert & 71.4 & 0.0 & 2.0 & 0.0 & 2.0 & 18.4 & 0.0 & 4.1 & 2.1 \\
\hline 2. Normal & 0.0 & 82.3 & 0.0 & 0.0 & 0.0 & 13.3 & 0.0 & 4.4 & 0.0 \\
\hline 3. Neurotic-Introvert & 0.0 & 0.0 & 71.9 & 0.0 & 3.1 & 0.0 & 15.6 & 9.4 & 0.0 \\
\hline 4. Neurotic-Hostile & 0.0 & 0.0 & 2.8 & 58.3 & 0.0 & 0.0 & 2.8 & 22.2 & 13.9 \\
\hline 5. Unassertive-Conformist & 0.0 & 0.0 & 2.6 & 0.0 & 94.8 & 0.0 & 0.0 & 2.6 & 0.0 \\
\hline \multicolumn{10}{|l|}{ Comparison groups } \\
\hline 6. Social drinkers & 30.3 & 13.3 & 3.3 & 3.3 & 6.7 & 26.5 & 3.3 & 10.0 & 3.3 \\
\hline 7. Depressed patients & 3.3 & 6.7 & 6.7 & 3.3 & 0.0 & 0.0 & 70.0 & 3.3 & 6.7 \\
\hline 8. Criminal & 10.0 & 3.3 & 10.0 & 16.7 & 10.0 & 16.7 & 6.7 & 13.3 & 13.3 \\
\hline 9. Alcoholics & 10.0 & 3.3 & 10.0 & 16.7 & 3.3 & 0.0 & 6.7 & 0.0 & 50.0 \\
\hline
\end{tabular}

Note. $\quad$ DUI $=$ driving under the influence.

terms such as cooperative, agreeable, traditional, simple, oldfashioned, predictable, and down-to-earth (Johnson, in press). Normal DUIs had the highest annual income of all DUI clusters $(\$ 15,022)$, the second lowest MF score (48.8), and the lowest IMP score (2.96). Although perhaps the best adjusted of all of the DUI types, these relatively normal individuals still exhibit drinking problems.

\section{Cluster 3 (Neurotic-Introvert)}

Cluster 3 most closely resembled clinically depressed patients. The profile configurations of this DUI group and depressed patients were nearly identical (below average scores on Prudence, Sociability, and Likability, with even lower valleys on Adjustment and Ambition for a I-IV- configuration), although the patients had much lower Adjustment scores and higher Prudence scores. Both profiles indicate a pattern of passivity, lack of energy, guilt, anxiety, social incompetence, low self-esteem, and depression (R. Hogan, 1986). Cluster 3 was therefore labeled Neurotic-Introvert. This cluster was further distinguished by their relatively high scores on MF (71.1) and IMP (4.84).

\section{Cluster 4 (Neurotic-Hostile)}

Cluster 4 was distinguished by relatively low scores on Likability and Adjustment (II-IV-). The Likability score is by far the lowest of any DUI or comparison group. In this pattern, they most closely resembled the criminal comparison group. Persons with this profile would likely be seen by others as tense, impatient, moody, irritable, cold, unreliable, and self-centered (Johnson, in press). This cluster, labeled Hostile-Neurotic, was the youngest ( 28.6 years), had the lowest annual income (\$7,361), and the highest MF score (71.7) and IMP score (5.31) of all DUI types. These figures are comparable to the criminal comparison group (28.7 years, $\$ 7,607$ in annual income, 83.9 on the MF, and 6.67 on the IMP, respectively).

\section{Cluster 5 (Unassertive-Conformist)}

Finally, the HPI profile for the remaining DUI cluster showed average scores on Adjustment, Prudence, and Likability, a low score on Sociability, and extremely low scores on Intellectance and Ambition $(\mathrm{I}-\mathrm{V}-$ ). Persons with this profile are described by others with terms such as agreeable, unambitious, and reminiscent (Johnson, in press), hence the label Unassertive-Conformist. This group was the oldest and demonstrated intermediate scores on MF (63.7) and IMP (3.42) indices. The Unassertive-Conformist type did not resemble any comparison group included in the study.

The HPI profile of the 30 alcoholics fits the description of an alcoholic "self-handicapper" (Berglas, 1985): low adjustment (marking anxiety and low self-esteem) with high sociability (marking a need for social approval). Although none of the DUI types showed primary resemblance to this profile, both Neurotic-Introvert and Neurotic-Hostile types showed some resemblance to the pattern. Although we did not find an alcoholic personality type in the DUI sample corresponding to our sample of clinical alcoholics, this does not mean that clinical alcoholism plays no role in the DUI problem. All of our DUI clusters exhibit problem drinking patterns, and the alcoholic label must surely be appropriate in some individual cases. Furthermore, we are not suggesting only one pure "alcoholic" type (see Morey, Skinner, \& Blashfield, 1984). We have merely demonstrated that none of our five personality types resembled our clinical sample.

Our results support previous research suggesting that the DUI population contains distinct personality subtypes (Donovan \& Marlatt, 1982). They based their conclusions on a questionnaire containing demographic variables, questions assessing drinking-related behaviors, and 17 short scales measuring driving attitudes and personality traits linked to accident risk in past research.

In this study, we used a well-validated measure of personality assessing the FFM of trait organization to interpret our results within an organizational and theoretical framework. Donovan and Marlatt's (1982) results were based on intrasample comparisons; that is, relative differences within their DUI sample. Their "depressed" cluster showed relatively high levels of depression compared with the remainder of their DUI sample, but it is uncertain how this group's level of depression compared with normal non-DUIs, clinically depressed non-DUIs, and so forth. The present study assessed both DUIs and distinctive 
non-DUI groups with a widely used, standardized personality inventory. This allows for normative comparisons and further clarification of the nature of personality types found in the DUI population.

In their study, Donovan and Marlatt (1982) identified two personality types who are at particularly high accident risk: a depressed, passive, resentful type and an aggressive, hostile, sensation-seeking type. Our results confirm the existence of two particularly maladjusted personality types-an introverted, emotionally distressed type (Neurotic-Introvert) and an egocentric, irritable type (Neurotic-Hostile). These two DUI types were the youngest, had the lowest average incomes, and demonstrated the highest MF and IMP indices. These two types resembled clinically depressed patients and incarcerated criminals, respectively. They appear to be the most deviant and possess the most risk-enhancing personality characteristics.

This study also identifies two less deviant DUI personality types-a group of somewhat careless Impulsive-Extraverts and a group of mild-mannered Normal types. The first exhibited good social adjustment and relatively light drinking; whereas the second exhibited relatively high social-status and scored low on risk-taking and aggression. These types resemble Donovan and Marlatt's (1982) "extraverted" and "normal" clusters. Although less than fully well-adjusted, these two groups appear to be at less risk than the Neurotic-Introvert and Neurotic-Hostile types.

The remaining personality type in the present study (Unassertive-Conformist) bears some resemblance to the Donovan and Marlatt (1982) cluster type that appeared preoccupied with control. They suggest that their "controlled" type is a milder version of the hypermasculine hostile type they identified. The Unasser tive-Conformist found in the present sample can be described as unintellectual, unambitious, reserved, conventional, and conforming, and may be unique to this sample. This type exhibited intermediate scores on the CRN indices and did not resemble any comparison group.

One practical application of the present study concerns the need for differential assessment and treatment programs for DUI offenders. Assessment of this sample using a widely applied inventory measuring the FFM and interpreting the results within such a framework provides a common descriptive language to apply to DUI subtypes. In general, Donovan and Marlatt's (1982) results were supported; however, there was no replicable way for service and counseling agencies to operationalize and assess such subtypes. A wide range of clinical assessment instruments have been related to the FFM (e.g., Costa \& McCrae, 1992a; McCrae, 1991). Assessing the five basic personality dimensions with DUI offenders in treatment can be achieved in a variety of ways. The presence of distinct personality types in the DUI population implies that people's motives for drinking and driving differ. These reasons can be considered when planning effective treatment interventions as it has been suggested that knowledge of normal personality information will aid in matching treatments to patients more effectively (Costa \& McCrae, 1992a, 1992b; Miller, 1991). With the emergence of the FFM, it seems appropriate to investigate the relative outcome of differential treatment programs across the personality types.

Some methodological caveats are in order. First, our sample was drawn from a semirural population in an area of high un- employment. Most DUI offenders make less than $\$ 20,000$ a year, and over half are unemployed. For this reason, conclusions regarding personality characteristics from this sample may not be completely generalizable to DUI offenders from metropolitan, high-employment areas.

Second, one question that could arise from our study is whether personality profiles of a selected sample (DUIs) differ at all from FFM profiles for the normal population. Recently, Lorr and Strack (1993) cluster analyzed NEO Personality Inventory (NEO-PI; Costa \& McCrae, 1985) profiles in a normal population and found six clusters. Using Johnson's (in press) FFM-based types, these clusters were: Stable-Extravert (I+IV+), Neurotic-Hostile (II-IV-), Hostile-Dependent (I-II-), Conscientious-Introvert (I-III+), Unconscientious-Neurotic (II+III-), and a Normal cluster with a flat profile. Two of these clusters, Neurotic-Hostile and Normal, are very similar to clusters found in this study. However, the differences among the remaining DUI clusters and those found by Lorr and Strack (1993) suggested that certain personality traits may increase one's risk for DUI behavior.

Third, one must be careful not to take self-reported behavioral impairment and quantity and frequency of drinking at face value. According to the CRN manual, persons with $\mathrm{MF}$ scores greater than 25 and blood-alcohol-content levels greater than $.15 \%$ at the time of arrest (which describes most of the DUI subjects) are underreporting impairment if IMP is less than 5.9 and underreporting QF if QF is less than 2.0. Such underreporting is a common part of a denial pattern in problem drinkers and may describe many of our subjects. Nonetheless, the relative differences between DUI clusters on underreported IMP and QF scores may still hold. It is possible that the lack of significant differences on QF scores among groups occurred because of an artificial ceiling effect on self-reported quantity inherent in the index.

A final caveat concerns the fact that the proportion of males to females in our comparison groups did not always approximate the largely male DUI population. However, HPI norms for males and females are highly similar (R. Hogan, 1986), and HPI profiles for the DUI clusters and their respective reference groups are similar despite the differences in male-female proportions. Had reference groups been primarily male, we might expect even greater profile similarity.

\section{References}

Barrick, M. R., \& Mount, M. K. (1991). The big five personality dimensions and job performance: A meta-analysis. Personnel Psychology, $44,1-26$.

Berglas, S. (1985). Self-handicapping and self-handicappers. In R. Hogan \& W. H. Jones (Eds.), Perspectives in Personality: Vol. 1 (pp. 235270). Greenwich, CT: JAI Press.

Briggs, S. R. (1992). Assessing the five-factor model of personality description. Joumal of Personality, 60, 253-293.

Buss, D. M. (1992). Manipulation in close relationships: Five personality factors in interactional context. Journal of Personality. 60. 477499.

Clay, M. L. (1972, September). Which drunks shall we dodge? Paper presented at the 23rd Annual Meeting of the Alcohol and Drug Problems Association of North America, Atlanta, GA.

Costa, P. T., Jr., \& McCrae, R. R. (1985). NEO Personality Inventory manual. Odessa, FL: Psychological Assessment Resources. 
Costa, P. T., Jr., \& McCrae, R. R. (1992a). Normal personality assessment in clinical practice: The NEO personality inventory. Psychological Assessment: A Journal of Consulting and Clinical Psychology, 4, 5-13.

Costa, P. T., Jr., \& McCrae, R. R. (1992b). Reply to Ben-Poratb and Waller. Psychological Assessment: A Journal of Consulting and Clinical Psychology, 4, 20-22.

Cronbach, L. J., \& Gleser, G. C. (1953). Assessing similarity between profiles. Psychological Bulletin, 50, 456-473.

Digman, J. M. (1990). Personality Structure: Emergence of the fivefactor model. Annual Review of Psychology, 41, 417-440.

Dixon, W. J., Brown, M. B., Engelman, L., Frane, J. W., Hill, M. A., Jennrich, R. I., \& Toporek, J. D. (1983). BMDP statistical software. Berkeley, CA: University of California Press.

Donovan, D. M., \& Marlatt, G. A. (1982). Personality subtypes among driving-while-intoxicated offenders: Relationship to drinking behavior and driving risk. Journal of Consulting and Clinical Psychology, 50, 241-249.

Donovan, D. M., Marlatt, G. A., \& Salzberg, P. M. (1983). Drinking behavior, personality factors and high-risk driving. Journal of Studies on Alcohol, 44, 395-428.

Donovan, D. M., Queissler, H. R., Salzberg, P. M., \& Umlauf, R. L. (1985). Intoxicated and bad drivers: Subgroups within the same population. Journal of Studies on Alcohol, 6, 375-382.

Hofstee, W. K. B., \& De Raad, B. (1992). Personality structure through traits. In G.-V. Caprara and G. L. Van Heck (Eds.), Modern personality psychology: Critical reviews and new directions (pp. 56-72). New York: Harvester Wheatsheaf.

Hogan, J., \& Hogan, R. (1986). Hogan personnel selection series manual. Minneapolis, MN: National Computer Systems.

Hogan, R. (1983). A socioanalytic theory of personality. In M. Page (Ed.) Nebraska symposium on motivation (pp. 55-89). Lincoln, NE: University of Nebraska Press.

Hogan, R. (1986). Hogan Personality Inventory manual. Minneapolis, $\mathrm{MN}$ : National Computer Systems.

Johnson, J. A. (in press). Computer narrative interpretations of individual profiles. In R. Hogan, J. A. Johnson, \& S. R. Briggs, (Eds.), Handbook of personality psychology. San Diego, CA: Academic Press.

Johnson, J. A., \& Ostendorf, F. (1993). Clarification of the five-factor model with the abridged big five dimensional circumplex. Journal of Personality and Social Psychology, 65, 563-576.

Lorr, M. (1983). Cluster analysis for social scientists. San Francisco: Jossey-Bass.

Lorr, M., \& Strack, S. (1993). Some NEO-PI five-factor personality profiles. Journal of Personality Assessment, 60, 91-99.

Lorr, M., \& Suziedelis, A. (1990). Distinctive personality profiles of the Interpersonal Style Inventory. Journal of Personality Assessment, 54, 491-500.

McCrae, R. R. (1991). The five-factor model and its assessment in clinical settings. Journal of Personality Assessment, 57, 399-414.

McCrae, R. R., \& John, O. P. (1992). An introduction to the five-factor model and its applications. Journal of Personality, 60, 175-215.

Miller, T. R. (1991). The psychotherapeutic utility of the five-factor model of personality: A clinician's experience. Journal of Personality Assessment, 57, 415-433.

Milligan, G. W. (1981). A review of Monte Carlo tests of cluster analysis. Multivariate Behavioral Research, 16, 379-407.

Milligan, G. W., \& Cooper, M. C. (1985). An examination of procedures for determining the number of clusters in a data set. Psychometrika, 50, 159-179.

Morey, L. C., Skinner, H. A., \& Blashfield, R. K. (1984). A typology of alcohol abusers: Correlates and implications. Journal of Abnormal Psychology, 93, 408-417.

Muten, E. (1991). Self-reports, spouse ratings, and psychophysiological assessment in a behavioral medicine program: An application of the five-factor model. Journal of Personality Assessment, 57, 449-464.

Nie, N. H., Hull, C. H., Jenkins, J. G., Steinbrenner, K., \& Bent, D. H. (1975). Statistical Package for the Social Sciences (2nd ed.). New York: McGraw-Hill.

Rao, C. R. (1952). Advanced statistical methods in biometric research. New York: Wiley.

Scoles, P., \& Cook, D. (1986). The Commonwealth of Pennsylvania's Court Reporting Network (CRN) program management and evaluation procedures manual (rev. ed.). Harrisburg, PA: Governor's Council on Drug and Alcohol Abuse of Pennsylvania (Contract No. ME8052) and Commonwealth of Pennsylvania Department of Transportation (Contract No. 63985).

Scoles, P., Fine, E. W., \& Steer, R. A. (1984). Personality characteristics in driving and drinking patterns of high-risk drivers never apprehended for driving while intoxicated. Journal of Studies of Alcohol, 45, 411-416.

Smith, T. W., \& Williams, P. G. (1992). Personality and health: Advantages and limitations of the five-factor model. Journal of Personality, $60,395-423$.

Snowdon, L. R. (1984). Treatment participation and outcome in a program for problem drinker-drivers. Evaluation and Program Planning, $7,65-71$.

SPSS, Inc. (1988). SPSS-X user's guide. Chicago, IL: Author.

Trapnell, P. D., Wiggins, J. S., \& Broughton, R. (1992). The structure of social reputations: Factor and circumplex analyses of the Hogan Personality Inventory. Unpublished manuscript, University of British Columbia, Vancouver.

Ward, J. H. (1963). Hierarchical grouping to optimize an objective function. Journal of the American Statistical Association, 58, 244263.

Widiger, T. A., \& Trull, T. J. (1992). Personality and psychopathology: An application of the five-factor model. Journal of Personality, 60 , 363-393.

Wiggins, J. S. (1973), Personality and prediction: Principles of personality assessment. Reading, MA: Addison-Wesley.

Wiggins, J. S. (1992). Have model, will travel. Journal of Personality, 60 , $527-532$.

Wiggins, J. S., \& Pincus, A. L. (1989). Conceptions of personality disorders and dimensions of personality. Psychological Assessment: A Journal of Consulting and Clinical Psychology, 1, 305-316.

Wiggins, J. S., \& Pincus, A. L. (1992). Personality: Structure and assessment. Annual Review of Psychology, 43, 473-504.

Wiggins, J. S., \& Pincus, A. L. (in press). Personality structure and the structure of personality disorders. In P. T. Costa, Jr., \& T. A. Widiger (Eds.), Personality disorders and the five-factor model of personality. Washington DC: American Psychological Association.

Wiggins, J. S., \& Trapnell, P. D. (in press). Personality structure: The return of the big five. In R. Hogan, J. A. Johnson, \& S. R. Briggs (Eds.), Handbook of personality psychology. San Diego, CA: Academic Press.

Received November 30, 1992

Revision received March 1, 1993

Accepted July 28, 1993 